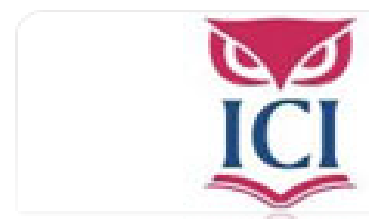

IUS. Revista del Instituto de Ciencias Jurídicas de Puebla A.C.

ISSN: $1870-2147$

revista.ius@hotmail.com

Instituto de Ciencias Jurídicas de Puebla A. C.

México

Andraca, Karina

Justificación para la concesión de beneficios de libertad anticipada

IUS. Revista del Instituto de Ciencias Jurídicas de Puebla A.C., núm. 19, 2007, pp. 155-187

Instituto de Ciencias Jurídicas de Puebla A. C.

Puebla, México 


\title{
JUSTIFICACIÓN PARA LA CONCESIÓN DE BENEFICIOS DE
} LIBERTAD ANTICIPADA

\author{
Karina Andraca*
}

SUMARIO

I. La finalidad del tratamiento PEnItenciario

II. TIPOS DE BENEFICIOS

III. IMPORTANCIA DE LOS BENEFICIOS DE LIBERTAD ANTICIPADA

iv. Principales causas que han generado SOBRepoblación PENITENCIARIA EN EL ESTAdo de Puebla

\section{RESUMEN}

En la actualidad la privación de la libertad se ha convertido en la sanción más importante, cuantitativa y cualitativamente, debido a que el Estado deposita en la cárcel su acción correctiva y utiliza a la prisión frecuentemente como una de las penas de mayor importancia. Esta sanción encuentra su fundamento constitucional en el artículo 18, en donde se establece que sólo por delito que merezca pena corporal, habrá lugar a prisión preventiva; pero contrariamente también en este precepto legal se impone como obligación a la federación y a los estados, organizar el sistema penal bajo un régimen basado en el trabajo, la capacitación para el

\section{ABSTRACT}

At the present time, the privation of the freedom has become the most important, quantitative sanction and qualitatively, because the State deposits in the jail its responsibility of correcting the social indisciplines and it frequently uses to the prison like one of the hardships of more importance. This sanction finds its constitutional foundation in the article 18 where hesettles down that only ex delicto that it deserves corporal punishment, there will be place to preventive prison; but contrarily also in this legal precept it is imposed as obligation to the Federation and the States, to organize the penal system, under a régime based on the work,

* Maestra en derecho penal y profesora de esta materia del Instituto de Ciencias Jurídicas de Puebla. 
mismo y la educación como principios rectores del proceso de readaptación social del delincuente. Esta norma encierra en su contenido dos finalidades que tiene que cumplir el sistema penitenciario: en primer lugar firmemente se propone readaptar, capacitar para el trabajo, educar, dignificar a la persona; y en el sentido opuesto tiene que propiciar la reparación de daños causados a las víctimas y a la sociedad, siendo esto un gran reto. En este artículo se explora la idea de la necesidad de favorecer a los sancionados por diversos delitos con la libertad anticipada y que la sociedad realice un mayor esfuerzo por su readaptación social. the training for the same one and the education like principles rectors of the process of social readaptation of the criminal. This norm locks in its content two purposes that has to complete the Penitentiary System: in the first place firmly intends to readapt, to qualify for the work, to educate, to dignify the person; and in the opposed sense she has to propitiate the repair of caused damages to the victims and the society, being this is a great challenge. In this article the idea of the necessity is explored of favoring those sanctioned by diverse crimes with the premature freedom and that the society carries out a bigger effort for its social readaptation.

Toda pena que no se derive de la absoluta necesidad es tiránica.

Montesquieu

En la actualidad la privación de la libertad se ha convertido en la sanción más importante, cuantitativa y cualitativamente, debido a que el Estado deposita en la cárcel su acción correctiva y utiliza a la prisión frecuentemente como una de las penas de mayor importancia.

Esta sanción encuentra su fundamento constitucional en el artículo 18, en donde se establece que sólo por delito que merezca pena corporal, habrá lugar a prisión preventiva; pero contrariamente también en este precepto legal se impone como obligación a la federación y a los estados, organizar el sistema penal (entendiéndose a éste como la organización creada para la ejecución de las sanciones penales - penas o medidas de seguridad-que importan privación o restricción de la libertad individual como condición sine qua non para su efectividad) bajo un régimen basado en el trabajo, la capacitación para el mismo y la educación como principios rectores del proceso de readaptación social del delincuente.

Como se puede observar, esta norma encierra en su contenido dos fina- 
lidades que tiene que cumplir el sistema penitenciario: en primer lugar firmemente se propone readaptar, capacitar para el trabajo, educar, dignificar a la persona; y en el sentido opuesto tiene que propiciar la reparación de daños causados a las víctimas y a la sociedad, siendo esto un gran reto.

Con lo enunciado podemos establecer que independiente del carácter retributivo de la prisión, en su sentido humanista busca la readaptación social, la cual es una garantía constitucional que forma parte de un sistema de normas. Su contenido normativo debe entenderse en armonía con los derechos de igualdad, tolerancia, legalidad y seguridad jurídica. La readaptación social no debe entenderse como una corrección moral coactiva basada en torturas. ${ }^{1}$ Tampoco puede aceptarse que para readaptar al sentenciado se puedan contravenir otras garantías como las antes mencionadas.

Esta readaptación social del delincuente de acuerdo a lo establecido por los artículos 2, 17, 19 de la Ley de Ejecución de Sanciones Privativas de la Libertad del Estado de Puebla, debe lograrse a través de un tratamiento institucional de carácter individual, progresivo y gradual, integrado por periodos de estudio y diagnóstico, tratamiento y de reintegración.

Lo anterior obedece a que la ley penal dispone la individualización del sujeto para fines de sentencia y, en lo que toca a la ejecución de las sanciones, para el tratamiento penitenciario. No sería justo aplicar la misma sanción a todos los delincuentes, aunque se trate de un solo género de delitos, ni darles el mismo tratamiento en reclusión, aunque se esté en presencia de condenas semejantes.

Así se impone realizar un estudio de personalidad que permita formular un diagnóstico e instituir, de forma individualizada, un tratamiento a través del cual se conozca al individuo más allá de lo que su expediente judicial indica con el propósito de desentrañar las causas del delito que ha cometido y disponer el tratamiento que debe aplicársele cuando se halla en prisión. Dada la complejidad de la conducta humana y la variedad de factores que en ella actúan, sería imposible que una sola persona versada sólo en una ciencia o disciplina, realice y valore el estudio integral de personalidad de todos los reclusos. Se necesita de un equipo en el que figuren conocedores de diversas disciplinas, esto es, un equipo técnico interdisciplinario, con atribuciones diversas y trascendentales, encontrándose entre las más importantes ser el conductor de este tratamiento individualizado.

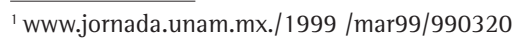




\section{La Finalidad del tRatamiento PENITENCIaRIO}

El principio rector número 60, de las Reglas Mínimas para el Tratamiento de los Reclusos (onu), cita: "Es conveniente que, antes del término de la ejecución de una pena o medida, se adopten los medios necesarios para asegurar al recluso un retorno progresivo a la vida en sociedad..."

Esto implica que durante la sucesión de los periodos del tratamiento, característica del sistema penitenciario progresivo, se prepare a hombres capaces de vivir en libertad. A esto se refiere el ideal de la readaptación social, que es motivo y razón de la pena privativa de la libertad. No es fácil que se prepare para la libertad a un sujeto que permanece recluido. ¿Cómo capacitar para la vida libre en cautiverio? Por ello se ha ideado la existencia de fases o etapas terminales de la reclusión, que representen, verdaderamente, un principio de acceso a la libertad: los beneficios de libertad anticipada.

\section{TIPOS DE BENEFICIOS}

En la legislación en materia de Ejecución de Sanciones del Estado de Puebla, se establecen tres tipos de beneficios de libertad anticipada:

- La libertad preparatoria.

- El tratamiento preliberacional.

- La remisión parcial de la pena.

Su finalidad es anticipar al reo en el contacto con la libertad, y se desarrolla en la etapa final de la reclusión. Se trata de sustituir ésta por un régimen diferente, de acercamiento a la futura excarcelación. Abarcan diversas medidas, entre las que se destacan: los permisos de salida, la prisión abierta, la remisión de días de prisión por trabajo, entre otras, siempre que se haya observado buena conducta por el reo en su reclusión y se demuestre con los estudios practicados por el Consejo Técnico Interdisciplinario que se encuentra readaptado y apto para reincorporarse a su núcleo social.

\section{IMPORTANCIA DE LOS BENEFICIOS DE LIBERTAD ANTICIPADA}

Como ya se ha mencionado, el artículo 18 constitucional y las leyes secundarias y reglamentos que regulan la actuación penitenciaria, establecen 
que el régimen y el tratamiento penitenciario debe de ser individualizado, progresivo y gradual, para que permita al reo adquirir conocimientos y habilidades que le faciliten su reincorporación a la sociedad, los cuales deben de basarse en el trabajo, la capacitación y la educación como medios para lograr su readaptación social; con motivo de esto la concesión de beneficios de libertad anticipada, contribuye a:

- Que el interno participe de manera constante en las actividades educativas, laborales, de capacitación, cívicas, artísticas, deportivas y culturales que se llevan a cabo en el centro penitenciario en el que se encuentra recluido.

- Que se cumpla cabalmente con la finalidad que contempla la prisión: la readaptación social del delincuente.

- Disminuir los índices de sobrepoblación.

- Que disminuyan los disturbios que se originan en los centros penitenciarios, tales como: riñas, muertes violentas, evasiones, suicidios.

\section{iv. Principales causas oue han generado sobrepoblación penitenciaria en el estado de Puebla}

Entre los principales factores que han contribuido a que los Centros de Readaptación Social del estado de Puebla se encuentren sobrepoblados, encontramos:

1. El rezago judicial.

2. El uso excesivo de la prisión.

3. La falta de capacidad económica del interno de cubrir el monto para garantizar su libertad provisional o bien el conmutar su pena privativa de la libertad por multa.

4. La inoperancia de la conmutación de la pena por trabajo a favor de la comunidad, y

5. La negativa y la prohibición de conceder beneficios de libertad anticipada.

Lo anterior se acredita con los siguientes gráficos:

En el estado de Puebla, se cuenta con una población penitenciaria de 6,116 internos y una sobrepoblación 1,606 internos, lo que equivale a $35.60 \%$. 
Del total de la población penitenciaria (6,116 internos), 5,540 son procesados o sentenciados por delitos del fuero común, lo que equivale a $90.58 \%$.

\section{POBLACIÓN PENITENCIARIA DEL FUERO COMÚN}

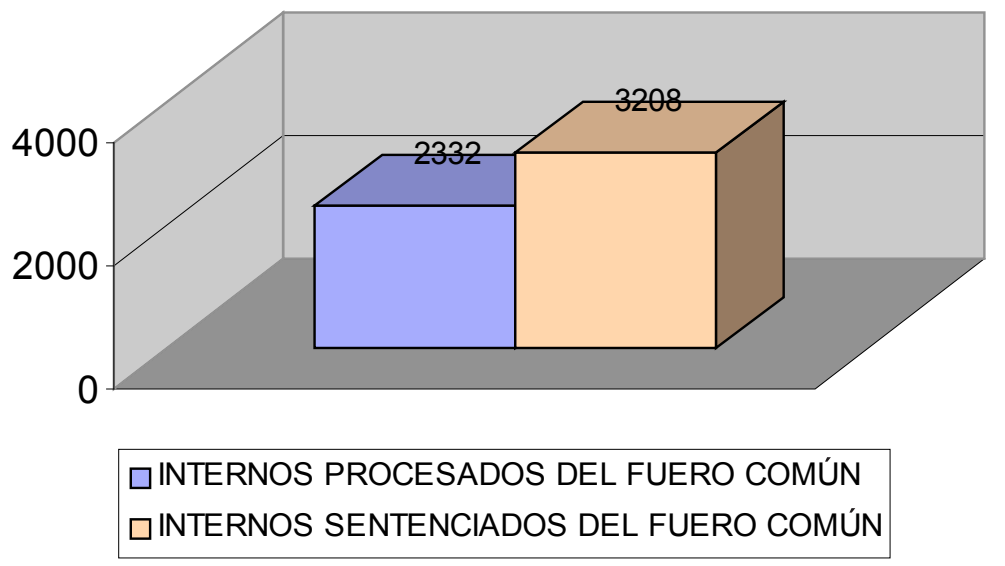

Del periodo comprendido del mes de diciembre de 1999 al mes de enero de 2003, se cuenta con 1,007 internos más (la población penitenciaria se incrementó de 5,109 a 6,116 internos), esto quiere decir que por cada año son recluidas en prisión 250 personas más.

Esta situación hubiera agravado notablemente la sobrepoblación penitenciaria del estado de no haberse concedido los 1,131 beneficios de libertad anticipada e iniciar en el mes de diciembre de 2001 la operación del Centro de Readaptación Social de Tepexi de Rodríguez con capacidad para 1,122 internos y haberse construido nuevos espacios en los Centros de Readaptación Social de Tehuacán, Tecali de Herrera y Puebla, lo que permitió ampliar la capacidad instalada de 3,032 a 4,510 espacios. 


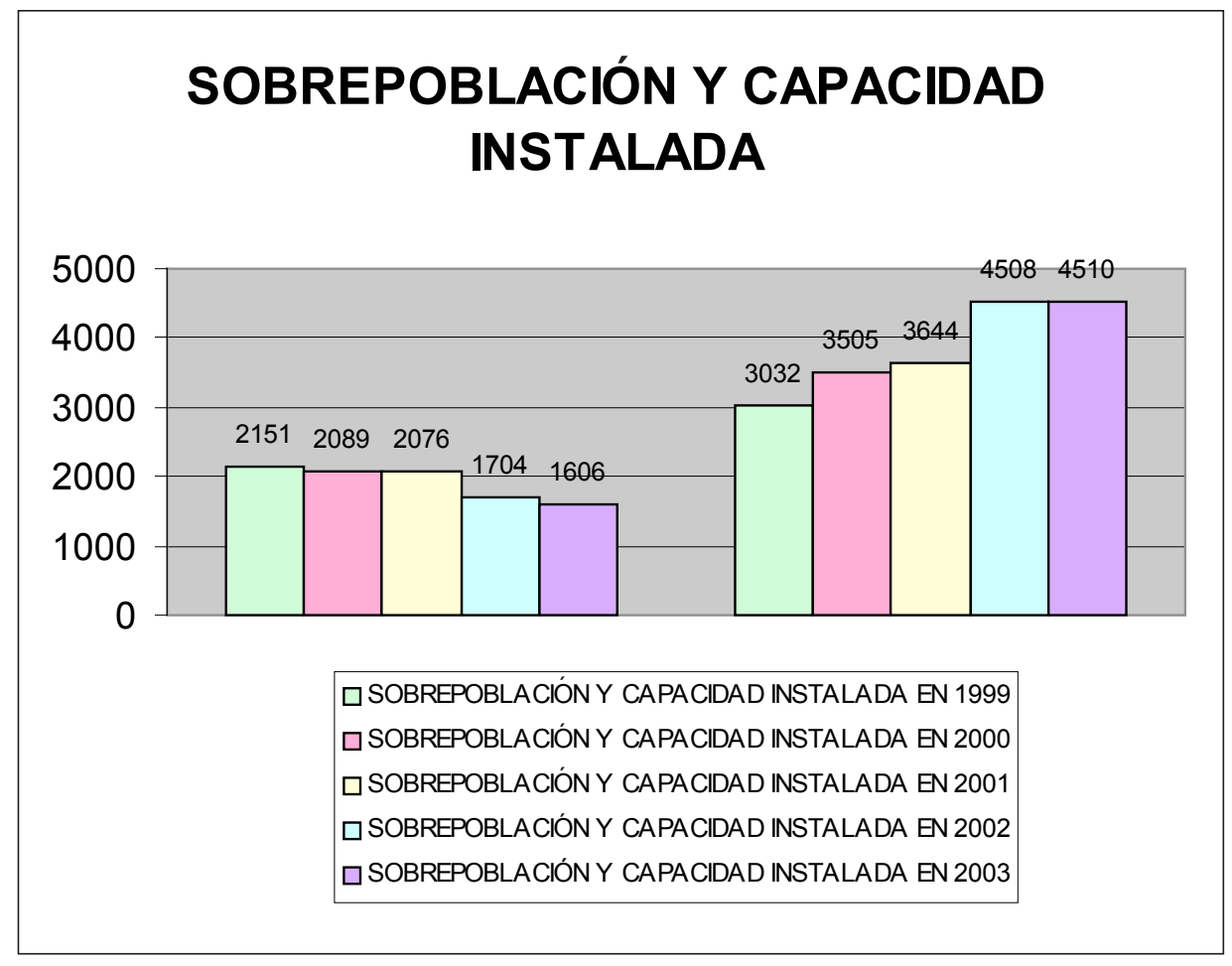

De no haberse concedido durante el periodo febrero 1999-diciembre 20021,131 beneficios de libertad anticipada y haberse ampliado 1,478 espacios en la capacidad instalada total del Sistema Penitenciario Estatal, en la actualidad se contaría con una sobrepoblación del 114\%, como se refleja en el siguiente grafico: 


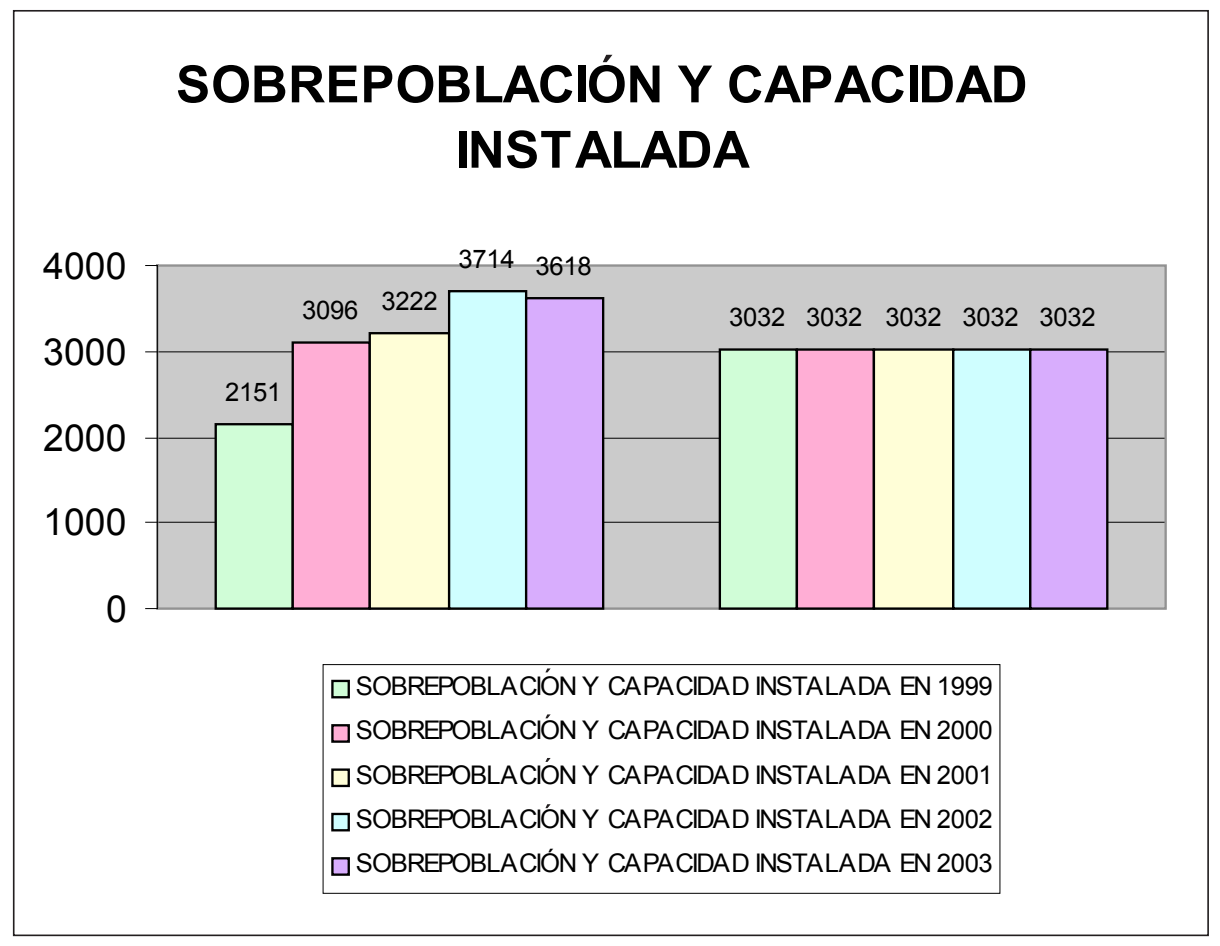

Más se agrava esta situación al abusarse de la privación de la libertad no sólo cuando se ejecutan las penas sino, lo más grave aún, cuando no se han dictado. En nuestro estado 2,436 internos se encuentran procesados y 3,680 se encuentran sentenciados, es decir el 39.82\% de la población penitenciaria se encuentra a disposición de la autoridad judicial. 


\section{POBLACIÓN PROCESADA}

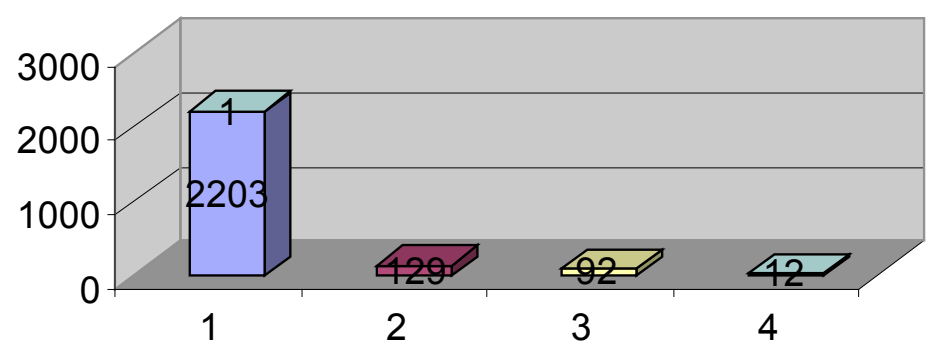

$\square$ MUJERES PROCESADAS F.F. $\square$ HOMBRES PROCESADOS F.F. 口MUJERES PROCESADAS FUERO COMÚN $\square$ HOMBRES PROCESADOS F.C.

No perdamos de vista que el procesado en materia penal no es otra cosa que un hombre sospechoso, presunto responsable de la comisión de un delito, al que por su condición de presunto le asiste el perfecto derecho de ser considerado como honrado mientas la justicia no afirme lo contrario.

De la población penitenciaria sentenciada (3,680 internos), solamente 3,208 corresponde a internos del orden común, lo que equivale a $52.45 \%$. 


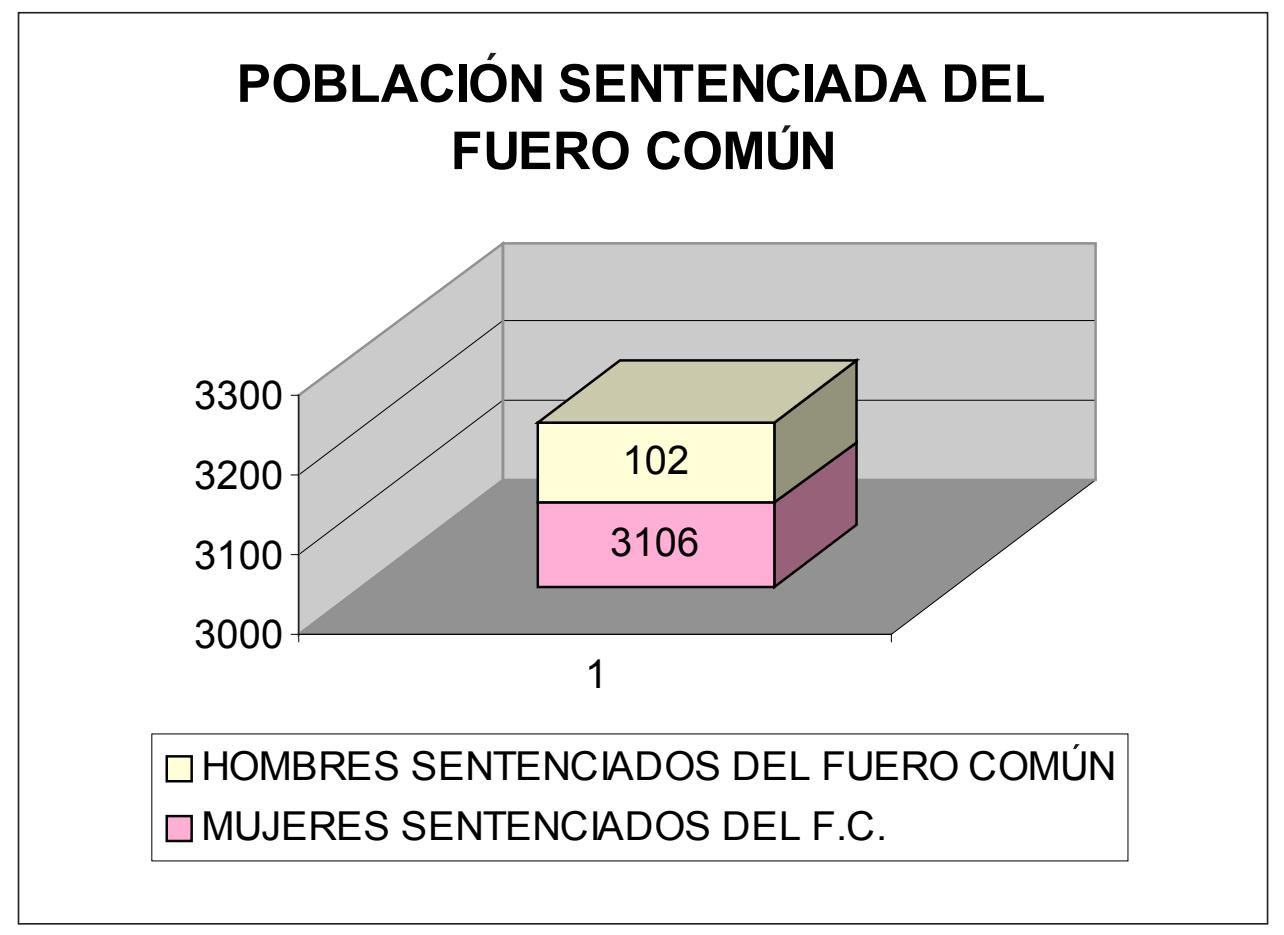


Ahora bien, si tomamos en consideración que de estos 3,208 internos sentenciados del fuero común, 1,292 no tienen derecho a ningún beneficio de libertad anticipada por haber cometido un delito grave (artículo 54 bis de la Ley de Ejecución de Sanciones Privativas de la Libertad) y 882 se encuentran sentenciados a cumplir una pena privativa de la libertad de más de 20 años de prisión, solamente 1,034 son candidatos a obtener algún beneficio de libertad anticipada, lo cual equivale únicamente a 16.90\% del total de la población penitenciaria.

\section{INTERNOS SENTENCIADOS DEL FUERO COMÚN}

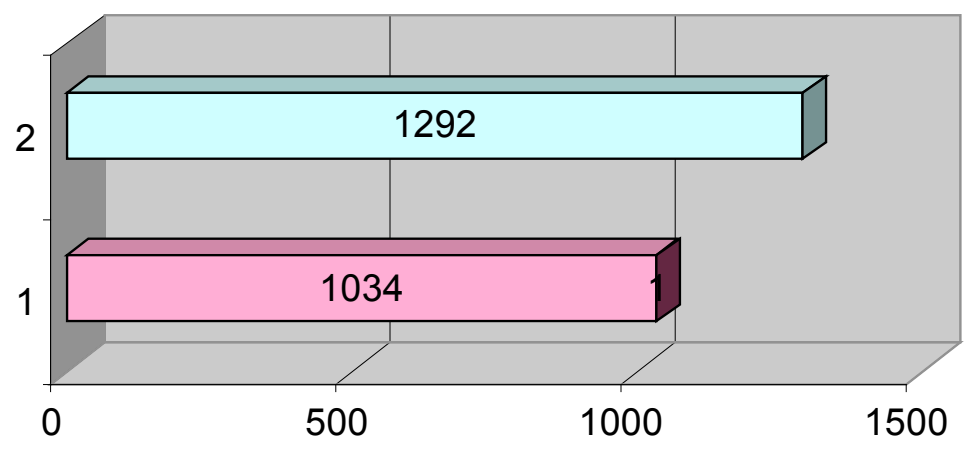

$\square$ INTERNOS DEL FUERO COMÚN SIN DERECHO A BENEFICIO DE LIBERTAD ANTICIPADA

INTERNOS DEL FUERO COMÚN CON DERECHO A UN BENEFICIO DE LIBERTAD ANTICIPADA 


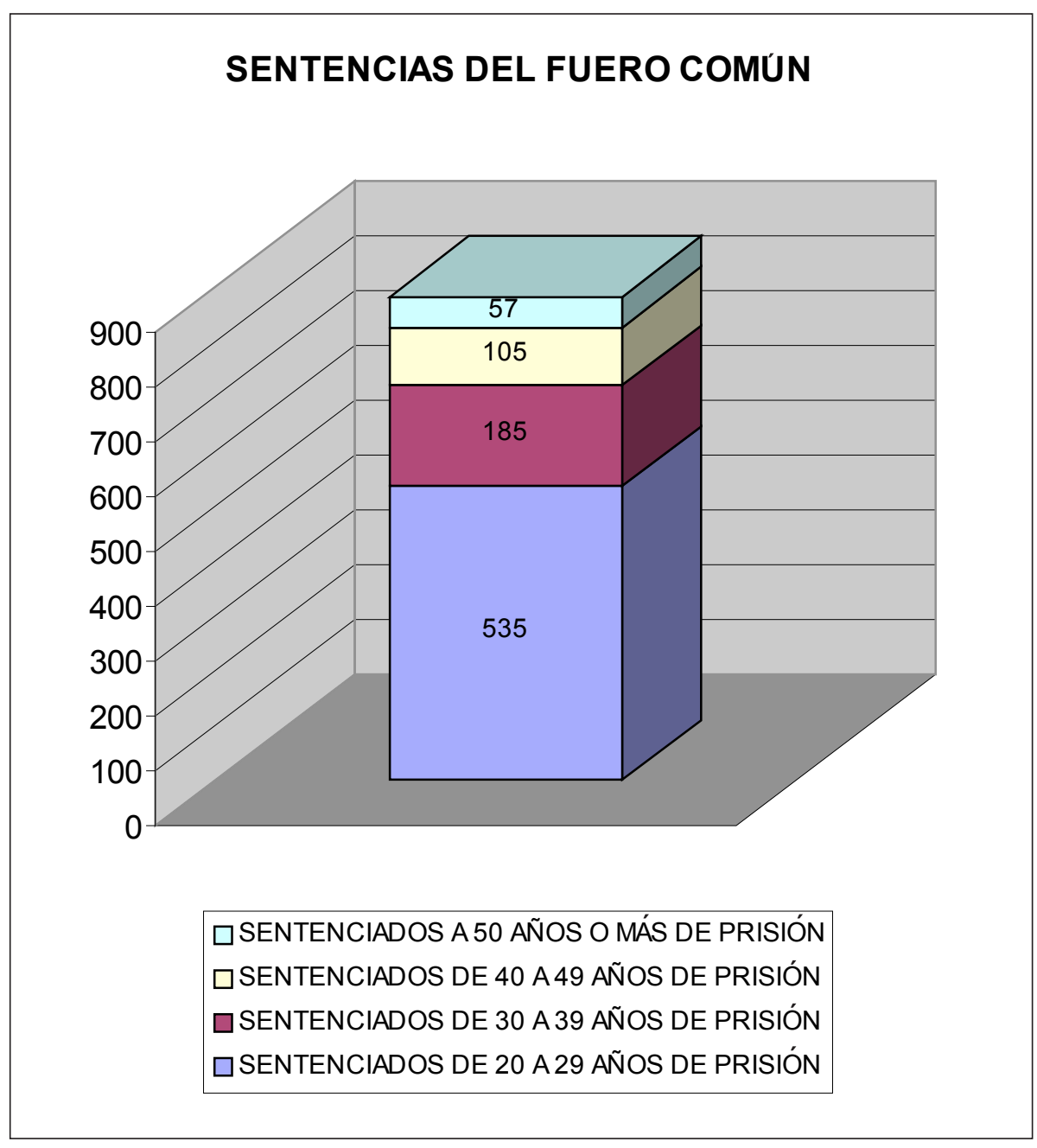

Si tomamos en consideración que 4,800 internos (lo que equivale al $78.48 \%$ del total de la población penitenciaria) se encuentran procesados o sentenciados por delitos considerados como graves y a partir del 27 de marzo de 1999, éstos no son candidatos a que se les conceda ningún beneficio de libertad anticipada (artículo 54 bis de la Ley de Ejecución de Sanciones Privativas de la Libertad) y de éstos 1,292 en la actualidad ya se encuentran en esta hipótesis, en un año más tendremos una sobrepoblación penitenciaria de 1,000 internos más. 


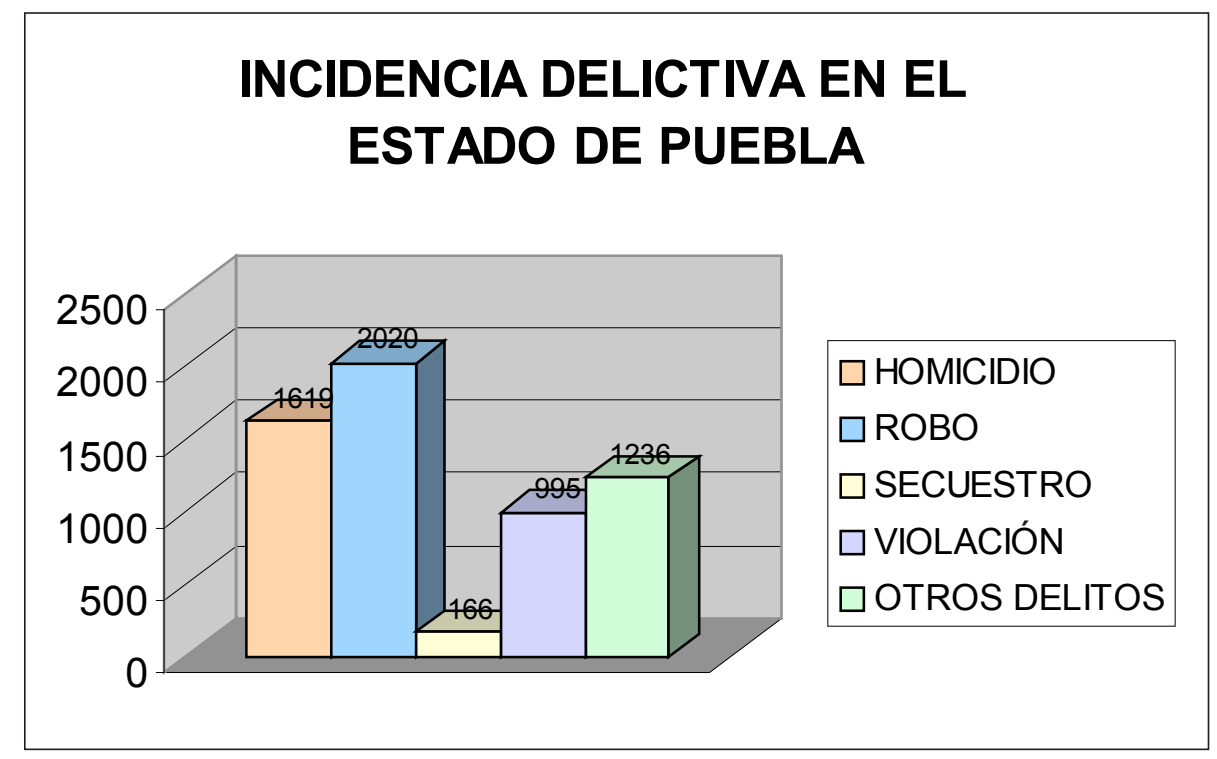

La libertad del hombre no debe restringirse sino en los casos absolutamente necesarios. Con motivo de lo anterior, resulta urgente que se realicen los trámites necesarios para que se concedan los 1,034 beneficios de libertad anticipada de los internos que tienen derecho a ella, ya que de lo contrario, en un año más el estado no tendrá la capacidad económica ni de infraestructura suficientes para albergar a más de 7,000 internos, lo que repercutirá indudablemente en el orden y la seguridad que debe imperar tanto en los Centros de Readaptación Social como en el exterior de ellos, ya que será motivo suficiente para que se generen riñas, evasiones y lo más grave: conatos de violencia que repercutirán en la etapa final de la administración pública actual.

Ante la evidencia del fracaso de la pena de prisión como instrumento para combatir el delito, podemos adelantar una hipótesis: los efectos nocivos de la vida carcelaria conducen inevitablemente a la contaminación de conductas antisociales de las personas que la padecen; mientras más permanecen en ella mayor será el riesgo. 


\section{EL SISTEMA PENITENCIARIO MEXICANO:}

A UN PASO DEL COLAPSO

José Luis Coca Muñoz

SUMARIO

I. Pena y PRISIÓN

II. Prisión y tratamiento

III. LA PRISIÓN Y SU FUNDAMENTACIÓN

IV. El tratamiento Penitenciario y SU ORIGEN

\section{RESUMEN}

La pena privativa de libertad, como su nombre indica, priva al penado de su libertad, recluyéndolo en un establecimiento penal y sometiéndolo a un régimen especial de vida y, por lo común, a la obligación de trabajar, aun cuando en nuestro país es un derecho para las personas sujetas a proceso, en tanto constituye una obligación para los sentenciados. El sistema penitenciario fue creado para reemplazar, con una finalidad humanitaria, la pena capital, el exilio, la deportación y diversos castigos corporales. Sin embargo, actualmente la prisión se ha convertido en una institución social con objetivos cada vez más complejos y contradictorios. Mientras que, en un principio, los establecimientos

\section{ABSTRACT}

The exclusive pain of freedom, as its name indicates, it deprives to the convict of its freedom, confining him in a penal establishment and subjecting it to a special régime of life and, in general, to the obligation of working, even when in our country, it is a right for people subject to process, as long as it constitutes an obligation for those sentenced. The penitentiary system was created to replace, with a humanitarian purpose, the death penalty, the exile, the deportation and diverse corporal punishments. However, the prison has become a social institution at the moment with more and more complex and contradictory objectives. While, in a principle, the penal establishments were created

* Doctor en derecho penal y profesor del Instituto de Ciencias Jurídicas de Puebla. 
penales fueron creados para ofrecer una forma nueva de sanción, en una época más cercana se ha tenido que aceptar que únicamente lo que hace es proteger a la sociedad, pero poco influye en modificar la conducta y las actitudes del delincuente y favorecer la reintegración social de éste. En este entorno, en México a pesar de estas grandes modificaciones realizadas, en honor a la verdad, las prisiones mexicanas representan el espejo negro de Tezcatlipoca, pues en su conjunto reflejan todas las injusticias de nuestra sociedad, las diferencias de clase, las miserias humanas, las perversiones, sus defectos e imperfecciones. to offer a new form of sanction, in a nearer time it has been had to accept that that only makes it is to protect the society, but little influences in to modify the behavior and the criminal's attitudes and to favor the social reinstatement of this. In this environment, in Mexico in spite of these big realized modifications, in honor to the truth, the Mexican prisons represent a hole injustice outside of all control, because in their group they reflect the inequalities of our society, the class differences, the human miseries, the perversions, their defects and imperfections.

\section{Pena y PRISIÓN}

Las sanciones penales en nuestro sistema jurídico al igual que otras en el mundo, están representadas por un amplio repertorio de reacciones que la sociedad ha tenido respecto al delincuente, pero en el momento en que la pena restrictiva de la libertad se empieza a utilizar como pena propiamente dicha, da lugar a que en gran medida quede relegada la pena de muerte, y se convierta en la más utilizada, no tan sólo en nuestro país, sino en la mayoría de los países del mundo.

Esto es, la prisión desde el momento en que sistemáticamente se le utiliza ya como pena, ha sido el medio favorito para tratar de punir y manejar a los delincuentes, aun cuando no se han abandonado totalmente otro tipo de penas (multa) que también se encuentran normatizadas en los códigos represores, así como tampoco ha cesado la búsqueda por encontrar otros medios penales con los cuales poder sustituirla; por ejemplo: trabajo a favor de la comunidad, arraigo domiciliario, etcétera.

A mayor abundamiento, se observa cómo los doctrinarios buscan explicar y fundamentar tanto los diversos tipos de sanción como sus fines 
y duración, tratando de encontrar una pena que sea lo suficientemente elástica para adecuarla al delito y muy posteriormente, al delincuente.

Esta búsqueda ha llevado hasta hoy a encontrar solamente una pena conocida con el nombre de prisión, lugar donde se le recluye a un delincuente sometiéndolo a un tratamiento penitenciario, significando una apreciable alternativa para sustituir la pena de muerte, las mutilaciones y las torturas aplicadas tiempos atrás a los delincuentes.

Sin embargo, el fin de la pena privativa de la libertad de lograr la "readaptación social" o "rehabilitación social", por medio del tratamiento o terapia, ha sido motivo de estudios en la doctrina penitenciaria, en las obras de los criminólogos y en numerosos congresos penitenciarios, como por ejemplo, el Octavo Congreso de las Naciones Unidas sobre Prevención del Delito y Tratamiento del Delincuente, celebrado precisamente en 1990 en La Habana, Cuba, sin olvidar uno último celebrado en El Cairo, Egipto, en el año de 1995.

\section{Prisión y tratamiento}

Con relación al término tratamiento, hasta hace algunos años no se discutía y se consideraba un magnífico avance progresista dentro de un contexto de humanización de las prisiones. Pero hoy en día las cuestiones han cambiado, pues se cuestiona severamente por parte de los estudiosos de la ciencia penitenciaria, ya que se ha hablado del tratamiento como si se tratase de una varita mágica para poder transformar a los delincuentes de hombres malos o perversos en hombres "buenos" de nuestra sociedad.

Es decir, "en la mayoría de leyes de ejecución penal quedó incluido dicho concepto (tratamiento) a partir del siglo xx, y en las leyes suecas de 1945, así como en las leyes de Holanda, Turquía, Checoslovaquia, Yugoslavia, Francia y Noruega en 1964, por citar sólo algunos países de la Europa occidental". ${ }^{1}$ Respecto a estas legislaciones lo más importante de ellas es que en la de Noruega, se señala como objetivo primordial del tratamiento el de mejorar en todo lo posible la aptitud y el deseo del recluso de seguir una vida conforme a la ley, una vez en libertad.

Refiriéndonos a nuestro país, se habla en nuestras leyes de ejecución penal del mismo término (tratamiento), buscándose con ello lograr la tan aventurada readaptación social del delincuente, o sea, la rehabilitación por

${ }^{1}$ Luis Marco del Pont, Derecho penitenciario, Editorial Cárdenas, México, 1995, p. 368. 
medio de la ejecución penal, debiéndose entender en el sentido de alcanzar la reeducación del delincuente, teniendo como parámetro la media éticocultural del ciudadano común y corriente.

En otras palabras, el penitenciarismo moderno mexicano persigue como fin último la readaptación o reinserción del delincuente a nuestro entorno social, a diferencia del antiguo penitenciarismo que a lo más que aspiraba era ejecutar un castigo para disuadir a futuro a quien violara el orden legal.

Para alcanzar dicho propósito se han hecho numeroso esfuerzos, y los especialistas en esta materia han establecido como elementos fundamentales: el tratamiento individualizado del preso, la existencia de instalaciones carcelarias adecuadas y el respaldo del cuerpo técnico especializado (pedagogos, criminólogos, psicólogos, trabajadores sociales y otros).

Pero aun cuando han sido magníficos los esfuerzos realizados en este aspecto por penitenciaristas de vocación, sólo por citar en esta ocasión a algunos: Javier Piña y Palacios, Antonio Sánchez Galindo, Sergio García Ramírez, Juan Pablo de Tavira, etc., puedo afirmar, sin temor a equivocación, lo siguiente: nuestro sistema penitenciario mexicano está muy lejos de poder lograr la verdadera rehabilitación social del infractor de la ley penal, pues son varios los factores que impiden de una buena manera lograr dicho propósito.

En sí, y retomando palabras textuales de Luis Fernando Quiñones y Alejandro Hernández Bringas, de su obra denominada Reforma integral penitenciaria, con relación a la readaptación, sucede lo siguiente: "la doctrina de la readaptación social es para los penitenciaristas mexicanos lo que el Santo Grial para los cristianos; todos lo veneran, pero nadie sabe dónde se encuentra ni cómo es empíricamente, sólo conocen cómo se originó la leyenda y quiénes la difundieron. Lo más grave del asunto es que su búsqueda nunca llega a su fin, y, por consiguiente, es uno de los mitos más extraños creados por los criminólogos".

\section{Prisión Y SU fundamentación}

Aún así, nuestro sistema penitenciario encuentra su base fundamental en el artículo 18 constitucional federal y dada su importancia, a continuación me permitiré transcribirlo:

${ }^{2}$ Luis Fernando Roldán Quiñones, et al., Reforma penitenciaria integral, Porrúa, México, p. 119. 
Artículo 18. Sólo por delito que merezca pena corporal habrá lugar a prisión preventiva. El sitio de ésta será distinto del que se destinare para la extinción de las penas y estarán completamente separados.

Los gobiernos de la Federación y de los Estados organizarán el sistema penal, en sus respectivas jurisdicciones, sobre la base del trabajo, la capacitación para el mismo y la educación como medios para la readaptación social del delincuente. Las mujeres compurgarán sus penas en lugares separados de los destinados a los hombres para tal efecto.

Los gobernadores de los Estados, sujetándose a lo que establezcan las leyes locales respectivas, podrán celebrar con la Federación convenios de carácter general, para que los reos sentenciados por delitos del orden común extingan su condena en establecimientos dependientes del Ejecutivo Federal.

La Federación y los Estados y el Distrito Federal establecerán, en el ámbito de sus respectivas competencias, un sistema integral de justicia que será aplicable a quienes se atribuya la realización de una conducta tipificada como delito por las leyes penales y tengan entre doce años cumplidos y menos de dieciocho años de edad, en el que se garanticen los derechos fundamentales que reconoce esta Constitución para todo individuo, así como aquellos derechos específicos que por su condición de personas en desarrollo les han sido reconocidos. Las personas menores de doce años que hayan realizado una conducta prevista como delito en la ley, sólo serán sujeta a rehabilitación y asistencia social.

La operación del sistema en cada orden de gobierno estará a cargo de instituciones, tribunales y autoridades especializados en la procuración e impartición de justicia para adolescentes. Se podrán aplicar las medidas de orientación, protección y tratamiento que amerite cada caso, atendiendo a la protección integral y el interés superior del adolescente.

Las formas alternativas de justicia deberán observarse en la aplicación de este sistema, siempre que resulte procedente. En todos los procedimientos seguidos a los adolescentes se observará la garantía del debido proceso legal, así como la independencia entre las autoridades que efectúen la remisión y las que impongan las medidas. Éstas deberán ser proporcionales a la conducta realizada y tendrán como fin la reintegración social y familiar del adolescente, así como el pleno desarrollo de su persona y capacidades. El internamiento se utilizará sólo como medida extrema y por el tiempo más breve que proceda, y podrá aplicarse únicamente a los adolescentes mayores de catorce años de edad, por la comisión de conductas antisociales calificadas como graves.

Los reos de nacionalidad mexicana que se encuentren compurgando penas en países extranjeros, podrán ser trasladados a la República para que cumplan sus condenas con base en los sistemas de readaptación social previstos en este artículo, y los reos de nacionalidad extranjera sentenciados por delitos del orden federal en toda la República, o del fuero común en 
el Distrito Federal, podrán ser trasladados al país de su origen o residencia, sujetándose a los tratados internacionales que se hayan celebrado para ese efecto. Los gobernadores de los Estados podrán solicitar al Ejecutivo Federal, con apoyo en las leyes locales respectivas, la inclusión de reos del orden común en dichos tratados. El traslado de los reos sólo podrá efectuarse con su consentimiento expreso.

Los sentenciados, en los casos y condiciones que establezca la ley, podrán compurgar sus penas en los centros penitenciarios más cercanos a su domicilio, a fin de propiciar su reintegración a la comunidad como forma de readaptación social.

En ese sentido, la Constitución Política de 1917 adopta para efectos de un tratamiento penitenciario, las siguientes clasificaciones: una de tipo jurídico, en el sentido de que de ahora en adelante los detenidos deberán descontar sus penas en lugares separados: los procesados en una parte, los sentenciados en otra. La otra clasificación adoptada es de tipo criminológico: las mujeres deberán estar separadas de los hombres, así como los menores de los adultos.

Cabe resaltar el hecho de que con la reforma al párrafo cuarto y las respectivas adiciones a los párrafos quinto y sexto del artículo 18 de nuestra Constitución, se fijaron las bases y lineamientos a partir de los cuales quedara asegurada la integralidad de un sistema de justicia para menores, en el que se incorporaron los principios de derecho nacional e internacional en el respeto y protección de los derechos humanos de las niñas, niños y adolescentes.

Dichas clasificaciones constituyen la piedra angular del tratamiento penitenciario, basado en tres puntuales: en el trabajo, la capacitación para el mismo y la educación como medios para la readaptación social del delincuente.

En este aspecto, la expresión tratamiento penitenciario, viene empleada en dos acepciones muy amplias: mientras desde un punto de vista jurídico, "el tratamiento es el régimen legal y administrativo que sigue a la emanación de la sentencia; de otro punto de vista criminológico, es en cambio, aquel complejo de actividades organizadas en el interior de un instituto carcelario a favor de los detenidos (actividades laborativas, educativas, culturales, deportivas, recreativas, médicas, psiquiátricas, religiosas, asistenciales, etc.), dirigidas básicamente a la reeducación y a la recuperación del reo y a su reincorporación a la vida social".

${ }_{3}^{3}$ Jorge Ojeda Velázquez, Derecho de ejecución de penas, Porrúa, México, p. 165. 
En otras palabras, el doctor Jorge Ojeda Velázquez expresa en su libro Derecho de ejecución de penas, lo siguiente: "el tratamiento debe ser visto como una verdadera y propia terapia, teniendo por objeto curar y sanar a quien ha errado, sea mediante una actividad práctica continua, o bien mediante una obra de constante sostén moral que ayude primeramente al sujeto a tener confianza en sí mismo y sobre todo a adquirirla con relación a aquellos técnicos ocupados de su reeducación".

Continuando con lo mismo, la confianza es, en efecto, una de las condiciones indispensables del tratamiento, porque solamente gracias a ella, el sujeto entrará en un clima de simpatía y de comunión con los operadores de su reeducación, aceptará de buena manera el tratamiento y colaborará activamente para lograr un buen resultado del mismo.

Por lo tanto, podemos comprender a simple vista, la siguiente premisa: teniendo en cuenta la delicadeza y la complejidad de las actividades requeridas para la actuación de un tratamiento penitenciario, es necesaria la colaboración no sólo de los expertos en las materias sociológicas, psicológicas, pedagógicas, médicas y criminólogos, quienes para la reeducación de los detenidos no sólo se sirven de sus métodos científicos, sino también de un personal de custodia altamente calificado que haya recibido una preparación cultural y espiritual propia al fin encargado o encomendado.

Resalta en este aspecto, el hecho de manifestar que de todo este personal, es de vital importancia la función realizada por el personal de custodia. No con esto quiero decir que es el más importante, sino que todos en su conjunto podrán realizar un eficaz tratamiento, pero sobre todo este personal al estar en contacto continuo con los detenidos, llegará a tener la facilidad y posibilidad de instaurar con ellos una verdadera y sincera relación humana, la cual será útil como consecuencia para la administración penitenciaria, pues de esta manera tendrá manera de conocer más a fondo tales sujetos, ocurriendo lo mismo con los detenidos, al sentirse de cierta forma menos solos.

Pero, basta preguntarse lo siguiente: ¿en realidad esto sucede en nuestros centros penitenciarios mexicanos?, o quizá haciendo la pregunta más extensa: ¿sucede en todas las cárceles o como se les quiera llamar del mundo entero?

La respuesta deberá ser contestada por la mayoría de los expertos, en sentido negativo, claro. Por desgracia las relaciones personales de custodia con los detenidos han seguido simplemente una línea de extremo rigor: los custodios se han sentido los representantes de la justicia y los tutores de 
la sociedad y no han tenido ninguna forma de compasión, ni han tenido algún tipo de sentimiento de piedad en relación con aquellos que atentan o infringen los valores sociales cuyos lineamentos mínimos se encuentran vaciados en los códigos punitivos.

Y respecto al tratamiento, podemos constatar cómo actualmente en el sistema penitenciario mexicano, el único tipo de tratamiento conocido es aquel efectuado en un establecimiento penitenciario.

Es decir, el único medio empleado para defender a la sociedad del sujeto que ha errado, es aquel de encerrar al delincuente en uno de los institutos, ya sea para arrestados, de custodia preventiva, de ejecución de penas o medidas de seguridad, o en el último de los casos de someterlo a un régimen de vida previamente establecido y buscar reeducarlo con el auxilio de los medios previstos en la Constitución Política Mexicana; sin dejar de lado algunas otras leyes secundarias como la Ley de Normas Mínimas sobre Readaptación Social de Sentenciados de 1971, el Código Penal o en los reglamentos internos de los centros de reclusión.

Estos medios contemplados en dichos cuerpos normativos, son los siguientes: "el trabajo, la instrucción, la capacitación técnica, los contactos con el mundo exterior entre los que sobresalen los coloquios del detenido con el defensor, amigos y familiares, la visita íntima y las actividades culturales, recreativas y deportivas, además de las religiosas".

Sin lugar a dudas todos estos medios representan un enorme valor, ya que en torno a éstos gira prácticamente todo el tratamiento penitenciario.

De esta forma al trabajo se le reconoce el mérito de combatir el ocio, de sacudir al detenido del aburrimiento físico y moral, de templar su cuerpo en la disciplina y sostenerlo espiritualmente haciéndolo sentir en cualquier tiempo útil para la vida en sociedad.

A la instrucción va el mérito de combatir la ignorancia, siendo a menudo la causa principal de las infracciones cometidas, y de elevar el espíritu, a fin de que el hombre no esté más sujeto a su instinto, sino a su libre albedrío.

Las actividades culturales, recreativas y deportivas tienen el mérito de mejorar el nivel cultural, las condiciones físico-psíquicas de los detenidos; las de apagar por parte de los detenidos cualquier situación de agresividad, pues esta causa desgraciadamente siempre se encuentra presente en los centros de reclusión.

\footnotetext{
${ }^{4}$ Ibid., p. 198.
} 
A la religión podemos reconocerle el mérito de confortarlo espiritual y moralmente, así como de infundirle la resignación cristiana, de hacerle revalorar el significado del bien y de hacerle sentir el deseo de sentirse en paz con sí mismo y con la humanidad.

A los coloquios epistolares y telefónicos del interno con el mundo extramuros, podemos reconocerle la función de no hacerlos sentir aislados y alejados de la vida cotidiana de la ciudad, para de esta forma seguir conservando, fortaleciendo y restableciendo las relaciones familiares, de amistad y de compañerismo olvidados por encontrarse privados de su libertad personal.

A la visita íntima se le reconoce el mérito doble de lograr en mucho la salud psíquica del detenido como aquél de reinstaurar las relaciones entre cónyuges o de quien constituye en la libertad su compañera.

Una vez analizados en teoría algunas consideraciones acerca del tratamiento penitenciario, sería prudente preguntarse: ¿cuál es el tipo de tratamiento seguido por nuestro país? Y, ¿cuáles son las diferentes etapas por las que atraviesa un interno para lograr su completa rehabilitación a la sociedad?

\section{El tRAtamiento PENitenciario Y SU ORIGEN}

Ante esta situación, el modelo vigente en la república mexicana se encuentra organizado sobre la base del sistema penitenciario progresivo. Éste consiste, a decir de sus insignes ideólogos, en alcanzar la rehabilitación social mediante etapas o grados progresivos.

Este sistema progresivo "parte de la premisa de que el infractor de la ley penal está dañado en su personalidad, y dicha rehabilitación deberá empezar con un estudio amplio, donde se abarcará su nivel socioeconómico, cultural, educativo, y sobre todo poder determinar con precisión las causas que lo orillaron a cometer el delito". ${ }^{5}$

Cabe hacer notar que en México el sistema aludido lo instauró don Miguel S. Macedo, jurista de clara formación positivista quien, basándose en las experiencias del irlandés Walter Crofton, formuló el proyecto penitenciario en 1897, mismo que tiempo después dio origen a la penitenciaría de Lecumberri en 1902. "Para Macedo, la idea principal radicaba en corregir al delincuente corregible y castigar sin infamia ni horror al incorregible."

${ }^{5}$ Alejandro H. Bringas, et al., Las cárceles mexicanas, Grijalbo, México, 1998, p. 25.

${ }^{6}$ Ibid., p. 26. 
No obstante, es José Almaraz quien a partir de la primera década de este siglo lleva a la práctica el proyecto de Miguel S. Macedo, pudiendo afirmar que es el primer penitenciarista mexicano que combina la teoría con la práctica. Entre sus grandes preocupaciones sobre la materia penitenciaria, decía que su trabajo penitenciario buscaba "modelar, reformar, curar o readaptar al delincuente".

Asimismo, cabe mencionar que Almaraz inició en 1944 la instrucción del personal penitenciario al aplicar un plan para criminólogos, funcionarios de cárceles y empleados de las mismas. Su mayor preocupación aparte de la anterior, se centró en el tratamiento de los presos conforme a la clasificación previamente definida, la disciplina interior para prevenir fugas, motines, etcétera.

Sin embargo y haciendo un recuento de la historia, debemos recordar que los antecedentes del sistema progresivo se encuentran en el Código Penal de 1931, donde ya se observaban algunos elementos relativos al tratamiento, como por ejemplo los permisos y salidas diurnas a los reos próximos a alcanzar el cumplimiento de su condena.

Más claro es el Código Penal de 1929, redactado por José Almaraz. Destacan, en relación con la ejecución de las sanciones, los siguientes elementos: a) la separación de los internos según "las especies de los delitos cometidos y las causas y móviles que hubieren averiguado en los procesos"; b) la diversificación del tratamiento procurando llegar a la individualización; c) la orientación del tratamiento en vista de la mejor readaptación del delincuente, y d) la normatividad relativa a la obligación del trabajo.

Aun así, desde el código de 1871, primer Código Penal mexicano, se sentía la necesidad de elaborar un buen código de procedimientos criminales, y otro penitenciario donde quedara reglamentado todo lo concerniente a las prisiones.

Esta última idea, evidentemente y a más de un siglo de distancia, fue inspiradora de la vigente ley que establece las normas mínimas sobre readaptación social de sentenciados, la cual fue promulgada en el año de 1971.

Esto es, nuestro jurista don Antonio Martínez de Castro, creador del primer código punitivo mexicano, como ya se dijo, tenía desde aquel tiempo un claro concepto de la armonía que debe reinar en materia penal, pues tanto el código de procedimientos criminales, y otro penitenciario, constituirian junto con el penal o sustantivo la verdadera legislación represiva, y estarian tan intimamente conexos entre sí, que al faltar uno de ellos quedaría truncado el todo que deben formar. 
La verdadera legislación represiva, como tan apropiadamente la llamaba Martínez de Castro, ha de unir sustancia penal, o sea, dogmática y delitos en particular con el procedimiento adecuado y con una clara legislación penitenciaria donde se reglamente todo lo concerniente a las prisiones.

Por lo tanto, es innegable desmentir cómo la Ley de Normas Mínimas, recogiendo el pensamiento de Martínez de Castro, reglamenta el trabajo, instrucción y educación de los presos; la distribución de sus ganancias, la formación de su fondo de reserva, la junta de vigilancia de las prisiones, la protectora de presos y todo lo demás relativo al régimen interior de las prisiones.

Además, esta ley significó desde su creación, el reconocimiento de la necesidad de normativizar formal y adecuadamente la ejecución penal, especialmente de los infractores de la ley penal quienes se encuentren sentenciados a cumplir alguna pena restrictiva de la libertad, esto es, con ella se alcanzó finalmente el ideal de existir una ley penal sustantiva, una ley de procedimientos penales y una ley de ejecución penal; siendo aprobada y ordenada su publicación el día 4 de febrero de 1971, para entrar en vigor treinta días después de su publicación en el Diario Oficial de la Federación el 19 de mayo de 1971.

En ella se ordena su aplicación en lo conducente, a todos los reos federales sentenciados en toda la República y la promoción de su contenido en todos los estados para su adopción.

Esta ley está organizada en seis breves capítulos, refiriéndose a los siguientes temas: el primero comprende las finalidades de la ley; el segundo, del personal penitenciario; el tercero, del sistema; el cuarto, de la asistencia a liberados; el quinto, de la remisión parcial de la pena -tipo de beneficio para concederle su libertad en forma anticipada-, y el sexto, de las normas instrumentales, contando, además, con cinco artículos transitorios.

Luego entonces, como una ley modelo, tiene las previsiones básicas relativas a los puntos citados, con el fin de orientar en el aspecto técnico penitenciario y en los demás enunciados en su capitulado a las entidades federativas en la adopción de un régimen progresivo técnico, congruente con las aspiraciones constitucionales y con los compromisos internacionales del país.

En cuanto a sus finalidades, el artículo primero establece principalmente la organización del sistema penitenciario en la República; por consiguiente, dicho sistema penal deberá ser organizado sobre la base del 
trabajo, la capacitación para el mismo y la educación como medios para la total rehabilitación social del delincuente.

Aún más, existen partidistas en el sentido de que no solamente se debe considerar al trabajo y a la educación como los únicos medios realistas para brindar un eficaz tratamiento penitenciario, sino también resaltan la importancia de incluir el tratamiento médico para conseguir su plena readaptación.

A mayor abundamiento, arguyen cómo la citada ley, en sus artículos subsecuentes, se refiere también a los sujetos alienados que hayan incurrido en conductas antisociales, respecto de los cuales lo fundamental no es el trabajo, ni mucho menos la educación, sino la curación.

Por último, el régimen penitenciario debe emplear, conforme a las necesidades individuales de cada interno, todos los medios disponibles: curativos, educativos, morales, espirituales, de asistencia o de cualquiera otra índole, ya que nuestro régimen penitenciario se caracteriza porque por medio de la readaptación del delincuente, pretendemos que cuando éste ingrese a la sociedad no solamente quiera llevar una vida normal bien adaptada y proveer a sus propias necesidades como miembro útil de la sociedad, sino también el ser capaz de hacerlo sin compulsión.

En ese sentido, para el tratamiento penitenciario la ley adopta el llamado -como ya se dijo en líneas anteriores- sistema progresivo individualizado, el cual debe tomar en cuenta las circunstancias personales del reo; y clasifica a los sentenciados para destinarlos a las instituciones especializadas más convenientes.

En realidad, se prepara al detenido, desde su ingreso al reclusorio, para su conveniente retorno a la sociedad, pues así debe interpretarse el artículo 7 de la Ley de Normas Mínimas sobre Readaptación Social de Sentenciados, que a la letra indica: "El régimen penitenciario tendrá carácter progresivo y técnico y contará, por lo menos, de periodos de estudio y diagnóstico y de tratamiento, dividido este último en fases de tratamiento, en clasificación y de tratamiento preliberacional. El tratamiento se fundará en los resultados de los estudios de personalidad que se practiquen al reo, los que deberán ser actualizados periódicamente."

Durante el periodo de estudio y diagnóstico, se realizará el estudio integral de la personalidad del interno desde los puntos de vista médico, psicológico, social pedagógico y ocupacional.

En otras palabras, en la primera fase quedará aislado en un cierto sentido el detenido y se analizará a fondo su personalidad. Esto permite formu- 
lar una diagnosis y un pronóstico y de establecer el tratamiento a seguir, para podérselo aplicar al sujeto, teniendo en cuenta todos sus aspectos: psiquiátricos, religiosos, laborales, etcétera.

Después de haber desarrollado este examen, se inicia el periodo dinámico de la reclusión y durante su desarrollo se observará continuamente al detenido (etapa de seguimiento), y con base en estas observaciones se podrán determinar las nuevas formas de tratamiento: en clasificación y en preliberación.

La clasificación de los detenidos constituye la mejor forma para lograr la individualización del tratamiento y tendrá como fin, entre otros, el de erradicar la promiscuidad, tan común en la mayoría de nuestras cárceles.

Asimismo, nuestra Constitución Política alude con relación a la clasificación, en su artículo 18, un criterio de clasificación jurídica de los detenidos, al indicar lo siguiente: "Sólo por delito que merezca pena corporal habrá lugar a prisión preventiva. El sitio de ésta será distinto del que se destinare para la extinción de las penas y estarán completamente separados..."

Esta separación existente entre procesados y condenados resulta tan acertada, habida cuenta que a favor de los primeros existe la presunción de inocencia y de inculpabilidad, toda vez que no existe una condena definitiva en su contra, a diferencia de los condenados, en cuya situación existe una condena definitiva, que resultaría contrario a los fines del tratamiento tener en una misma celda a un presunto responsable de un delito, con un delincuente reincidente, habitual o profesional.

Posteriormente, conforme a las reformas en 1965 al artículo 18 constitucional, se introdujo una ulterior clasificación de tipo criminológica, en donde deberían quedar completamente separados los hombres de las mujeres, así como los adultos de los menores.

El citado artículo constitucional en su segundo párrafo, parte final, empieza citando lo siguiente: "Las mujeres compurgarán sus penas en lugares separados de los destinados a los hombres para tal efecto..."

De igual forma y siguiendo esta clasificación de tipo criminológica, el párrafo cuarto del mismo artículo, a la letra indica: "La Federación y los Estados y el Distrito Federal establecerán, en el ámbito de sus respectivas competencias, un sistema integral de justicia que será aplicable a quienes se atribuya la realización de una conducta tipificada como delito por las

${ }^{7}$ Constitución Politica de los Estados Unidos Mexicanos, Porrúa, México, 2007, p.22. 
leyes penales y tengan entre doce años cumplidos y menos de dieciocho años de edad, en el que se garanticen los derechos fundamentales que reconoce esta Constitución para todo individuo, así como aquellos derechos específicos que por su condición de personas en desarrollo les han sido reconocidos. Las personas menores de doce años que hayan realizado una conducta prevista como delito en la ley, sólo serán sujetos a rehabilitación y asistencia social."

Con estas reformas nuevamente nuestra república mexicana vuelve a ponerse a la vanguardia en cuanto al sistema de ejecución de penas, pues se acoge el criterio constitucional de que la imputabilidad de una conducta tipificada como delito sólo es aplicable a partir de los dieciocho años cumplidos, donde todos aquellos menores de esa edad, tendrán garantizado el debido proceso de ley y todo el conjunto de derechos fundamentales inherentes a la persona humana y a los que específicamente les corresponden por su condición de personas en desarrollo. "Con ello se abordan los modelos garantistas que exigen la comunidad internacional y la sociedad mexicana en materia de derechos humanos de los menores."

A ese respecto, también la Ley de Normas Mínimas nos sigue dando lineamientos referentes a la clasificación de los reos, tomando en cuenta su peligrosidad social; así el segundo párrafo del artículo 6 establece lo siguiente: "Para la mejor individualización del tratamiento y tomando en cuenta las condiciones de cada medio y las posibilidades presupuestales, se clasificará a los reos en instituciones especializadas, entre las que podrán figurar establecimientos de seguridad máxima, media, mínima, colonias y campamentos penales, hospitales psiquiátricos y para infecciosos e instituciones abiertas." ${ }^{9}$

Una vez concluida esta fase del tratamiento, o sea, la aplicación de las medidas que se hayan considerado más adecuadas para su readaptación, se continuará con la última etapa: el tratamiento preliberacional.

El propósito de estos beneficios consiste en el de disminuir las señas personales sobresalientes del encarcelamiento y de crear una solución de continuidad, proyectada hacia la vida libre.

En dicho periodo preliberacional, la cárcel pierde su importancia que por definición significa aislamiento, y comienza a adquirir preponderancia la vida libre. Es en este periodo de tratamiento donde entran en juego

${ }^{8}$ Código de Justicia para Adolescentes del Estado Libre y Soberano de Puebla, "Exposición de motivos”, Porrúa, México, 2006, p. 2.

${ }_{9}^{9}$ Raúl Carrancá y Rivas, Derecho penitenciario, Porrúa, México, 1981, p. 521. 
ciertos beneficios y medidas jurídico-administrativas, señaladas por el artículo 8 de la Ley de Normas Mínimas, el cual enuncia que el tratamiento preliberacional podrá comprender: "Información y orientación especial, discusión con el detenido y con sus familiares sobre aspectos personales y prácticos de su futura vida en libertad. [...] Métodos colectivos. [...] Concesión de mayor libertad al interior del Reclusorio. [...] Transferimientos a un establecimiento abierto. [...] Permiso de salida de fin de semana o diaria con reclusión nocturna o bien salida en días hábiles con reclusión de fin de semana."

La concesión gradual de estos beneficios se hace cuando el detenido ha compurgado parte de la condena, o sea, ha cumplido con el tratamiento jurídico-criminológico dentro del instituto carcelario y está próximo a obtener su libertad.

De antemano sabemos que en esta etapa se producen procesos psicológicos en el individuo, y que el egreso abrupto de la institución penitenciaria puede producirle traumas, estados de shock e inclusive síndromes de desrealización, llevándolo inevitablemente a cometer nuevos delitos a fin de volver a su antiguo hábitat: la cárcel.

De ahí que a la manera de una convalecencia se ha pensado en estos beneficios preliberacionales, como preparación a la libertad, en virtud de acercarse en poco tiempo.

De esta manera, la fracción I del ya citado artículo 8 de la Ley de Normas Mínimas, señala la importancia de la participación de los familiares y amigos del detenido en la futura reintegración a su medio social.

Es decir, los familiares y amigos constituyen el marco fundamental del retorno y su comprensión y apoyo resultan por lo mismo indispensables, pues en la mayoría de los casos el detenido ha sido causa de disgustos, vergüenza y discusiones desagradables por parte de los suyos y por ello las relaciones familiares se encuentran rotas. No basta entonces, la sola personal preparación del detenido hacia su salida del establecimiento, sino la aceptación cordial, segura y desinteresada por parte de su familia y de sus amigos.

De esta manera se está uniendo al cuerpo destrozado anteriormente. Entonces, este entendimiento entre la familia y el detenido, no debe reposar en la emoción natural del momento, sino en la sólida preparación psicológica brindada a la familia para hacerle entender la situación personal de su detenido y acogerlo, sin parecer por ello la última oportunidad que se le desea otorgar. 
Asimismo, el detenido deberá aceptar la conducta familiar, en especial la de su cónyuge que durante el tiempo de su detención llevó sobre sus espaldas todo el peso del hogar, y por lo mismo la separación ha engendrado nuevas costumbres, actitudes, un concepto diferente de ver las cosas, a la cual el sujeto se debe atener.

Por último, la orientación especial brindada a todo exdetenido, debe de referirse a la conveniencia de no retornar al medio social en donde cometió el delito, porque la víctima o víctimas que en ocasiones pueden encontrarse en colonias o vecindades enteras, no verían con agrado la presencia de quien anteriormente les causó algún daño.

Con respecto a los métodos colectivos previstos en la fracción III del artículo 8 de la Ley de Normas Mínimas, constituyen otro paso adelante en la puesta en libertad de los detenidos. En efecto, no basta de ninguna manera mantener al individuo entre patios y dormitorios, talleres o la escuela, o cualquier otro lugar, que en poco o en nada tienen semejanza con el mundo real, con la sociedad libre, a la que han pertenecido por muchos años.

De ahí que los métodos colectivos a través de salidas periódicas a la comunidad tengan por objeto ilustrar a los detenidos acerca de la organización social, cultural y laboral, a la que todo ser humano pertenece. Este será un contacto firme con la realidad actual donde convivimos y una puesta al día con los cambios que la ciudad va sufriendo paulatinamente, de manera que después de 5, 10, 15, 20 años de encontrase privado de su libertad, el interno no se encuentre al momento de ser agraciado con este beneficio, en un mundo irreal, desconocido, y en el que pueda perderse tanto material como emotivamente.

Por otra parte, los detenidos en su mayoría pobres y con una escasa cultura, sólo han conocido una parte de ella, acaso la más insalubre y desprovista de todo medio educativo.

Es decir, como han pasado varios años en reclusión, lógico es que no han tenido la oportunidad, la invitación e información para asistir a los teatros, a conciertos musicales, a los museos, al cine, etc. Las salidas de los detenidos en grupos tienden a exterminar la imagen negativa que de los centros de reclusión, el público siempre ha guardado en mayores o menores proporciones.

El beneficio previsto por la fracción III del comentado artículo 8 de la Ley de Normas Mínimas, implica la concesión al detenido de una mayor libertad dentro del establecimiento. Sabemos que el primer día de reclusión 
para el detenido suele ser el derrumbe del universo, la pérdida total de su libertad cifrada en la esperanza de salvar su vida, el aniquilamiento de todo esfuerzo; y, por lo mismo es lógico que resienta un desajuste emocional, capaz de transformar su inteligencia en un espantoso estado depresivo -conocido con el nombre de "carcelazo"- ocasionando con ello inclusive modificar el ritmo biológico de su existencia.

Si a este panorama nada halagador, agregamos, por desgracia, una continua limitación en todos los órdenes a la que el recluido debe obedecer y sujetarse, no tiene nada más en su mente, sino la obsesión de poder ver el amanecer del día, en salir nuevamente libre.

Dentro de un marco puramente penológico, la fase preliberacional puede y debe surtir efectos desde el mismo centro penitenciario, concediendo al candidato a obtener la preliberación un mayor número de facilidades, accesos, beneficios, es decir, confiar en su tránsito por la institución, considerándolo no como un detenido más, sino más bien un próximo ciudadano preparándose para ingresar a la sociedad.

La finalidad de esta concesión de mayor libertad dentro del establecimiento, es la de hacer madurar las condiciones más simples, a fin que el detenido no se perturbe con el aire de la libertad y la absorba en pequeñas dosis.

Este desplazamiento del detenido por toda la institución y aún fuera de ella cuando sea autorizado, le dará más confianza y seguridad en sí mismo.

Respecto al traslado a una institución abierta, como instituye la fracción Iv del multicitado artículo 8 de la Ley de Normas Mínimas, constituye el punto final de la preliberación y al mismo tiempo, el punto de partida de las medidas alternativas a la detención, iniciándose ésta con la semilibertad. En aquélla, el detenido goza de una libertad absoluta, no hay rejas ni muros que impidan su fuga y el régimen de gobierno de esta institución, está basado en la autodisciplina y el autogobierno; en otras palabras, la institución abierta, reposa sobre dos aspectos: uno, objetivo o sustancial, consistiendo en la total ausencia de dispositivos materiales o físicos contra la evasión; y el otro de tipo subjetivo, que viene a ser la confianza en el detenido, en que el tratamiento aplicado dará sus frutos.

Pero, aun así, con todos estos magníficos adelantos legislativos, podemos asegurar que la institución penitenciaria se encuentra hundida en una profunda crisis de credibilidad y de legitimidad.

Es decir, el penitenciarismo, ejercicio programático del poder estatal y medida del derecho penal vigente aplicado entre los muros de las prisiones, ha sido objeto de severas críticas provenientes de distintos sectores 
sociales: instancias partidistas, gubernamentales, organismos religiosos y de defensa de derechos humanos.

A mayor abundamiento, a causa de sus actuales condiciones operativas, las cárceles mexicanas son instituciones generadoras de odio hacia las autoridades, de rencores, y representan en sentido estricto un factor altamente criminógeno. Y si profundizamos más, es la cárcel una institución anormal, pues con este calificativo se describe lo que se observa al llegar a una prisión: un medio artificial, donde deambulan extraños individuos con un semblante hostil, poco agradable, miradas que bien pueden ser de envidia, desconfianza, ironía o rencor... perdidos van de aquí hacia allá, cual autómatas ejecutores de una rutina aplastante, en pocas palabras, sujetos que al sucumbir a la monotonía hacen de sus modus vivendi una trágica e interminable agonía que los atormenta con el peso del remordimiento y la frustración.

Las condiciones de los penales mexicanos están por debajo de los niveles mínimamente aceptables de dignidad humana. En prácticamente todos los penales visitados del estado de Puebla, los internos están recluidos en dormitorios sucios, insalubres y sobrepoblados.

Estas causas se deben entre muchas otras a que nuestro sistema penitenciario se encuentra determinado por factores exógenos que delimitan sus características esenciales. En primer lugar, una maquinaria de procuración de justicia que en nombre del Estado y autoproclamándose la "representación social" o bajo la burlesca denominación de "Institución de Buena Fe", "ha concentrado un poder discrecional ejerciéndolo violentamente contra cualquier ciudadano a quien puede secuestrar, en virtud de que jamás presenta la respectiva orden de aprehensión dictada por los jueces, incomunicar durante días, intimidar a familiares, y sobre todo, torturar para obligarlo a declararse culpable de la comisión de un delito". ${ }^{10}$ Así es como, por medio de este mecanismo, miles de ciudadanos han ido a parar a las cárceles acusados injustamente.

En segundo lugar, en México prevalece la perversa tradición de castigar antes de comprobar la responsabilidad penal del inculpado. Esto es, primero se encarcela al individuo remitiéndolo a un reclusorio, en donde deberá demostrar su inocencia al juzgador, y sólo después logrará obtener su libertad. Ante esto, bien se puede decir que el principio de inocencia de todo procesado se encuentra de cabeza, pues se abusa indiscriminadamente de la prisión preventiva.

${ }^{10}$ Alejandro H. Bringas, et al., Op. cit., p. 20. 
Por lo tanto, el principio de inocencia quedaría totalmente olvidado y tendría que venir a ser sustituido por el siguiente: En México todo interno es culpable mientras no demuestre su inocencia... por eso se encuentra preso.

No basta elaborar reglamentos para detener la marea de la corrupción y la violencia institucionalizada, el tráfico de influencias, los privilegios, la drogadicción, las extorsiones, que conducen a las condiciones de vida degradante de la mayoría, impidiendo preparar al recluso para volver a la sociedad sin ánimo ni necesidad de delinquir.

En la violación sistemática del derecho penitenciario se encuentra la explicación exacta sobre el fracaso estrepitoso de la doctrina de la readaptación social del interno. Pero dicho fenómeno no es novedoso, tal y como lo afirma Michel Foucault, explicándolo de esta manera: "La prisión fabrica también delincuentes al imponer a los detenidos coacciones violentas; está destinada a aplicar las leyes y a enseñar a respetarlas; ahora bien, todo su funcionamiento se desarrolla sobre el modo de abuso de poder. La arbitrariedad que un preso experimenta es una de las causas que más pueden hacer indomable su carácter. Cuando se ve así expuesto a sufrimientos que la ley no ha ordenado ni aun previsto, cae en un estado de cólera contra todo lo que le rodea; no ve sino verdugos en todos los agentes de la autoridad, y por lo mismo no cree haber sido culpable y acusa a la propia justicia." 11

Es una institución depositada generalmente en manos de militares y judiciales, aporreadores e ignorantes en materia penitenciaria, y que por lo mismo no les interesa en nada lograr cumplir los objetivos de la pena restrictiva de la libertad: la readaptación social.

Además, esta institución penitenciaria, tal como opera actualmente, es costosísima, no sólo por el gasto que los contribuyentes sufragan, sino por los crecientes costos sociales que debe pagar, pues en las prisiones se profesionaliza la delincuencia en distintas actividades ilegales y al alcanzar la libertad ejerce su acción perniciosa en contra de la propia comunidad.

En otras palabras, la sociedad mexicana ha pagado elevadísimos costos a través de sus impuestos, y la cárcel no ha servido para readaptar al infractor de la ley penal, sino todo lo contrario, ha contribuido decisivamente para su profesionalización, por lo tanto, nos encontramos frente a una institución que ha fracasado.

En nuestras prisiones mexicanas los presos conviven todos los días en

"Michel Foucault, Vigilar y castigar, Siglo xxl, México, 1983, p. 271. 
los mismos espacios, sobre todo en las estancias, donde se desnudan, se bañan y en general están rodeados de una atmósfera en donde no existe la privacía. En los dormitorios predomina la sobrepoblación, obligándo a que los presos duerman juntos estrechamente, provocando que aflore el instinto sexual y alguno trate de poseer al compañero, situación que desemboca la mayoría de las ocasiones en sangrientas batallas.

Con relación a la problemática sexual de los internos, se ha combatido por medio de la visita conyugal que, dicho sea de paso, es un innegable logro del penitenciarismo mexicano. Cabe destacar que en muchos países no está autorizada y en algunos que la tienen, como España, se reduce a una sola vez al mes durante unas cuantas horas. En México la visita íntima existe desde 1924, en el Distrito Federal.

De esta forma la orientación de readaptación social que la Constitución quiere darle a la pena, debe entenderse como la finalidad hacia la que debe dirigirse la ejecución de la pena privativa de libertad. Ante esa situación, la ejecución o cumplimiento de las penas privativas de libertad deben ir acompañadas por toda clase de actividades en vías de ayudar al recluso en el desarrollo de su personalidad y su dignidad, manteniendo por separado el hecho de la readaptación, pues ésta no se logra sólo con la aplicación de la pena.

En sí, en México la cárcel sólo ha tenido un valor asegurativo en cuanto a la guarda del reo, pues no se realizan estudios de la personalidad del delincuente, ni mucho menos existe trabajo y educación dentro de los penales, representando todo ello un aspecto tan desolador, y sólo ve la sociedad a la prisión como su mejor defensa para combatir la criminalidad, y por lo mismo le basta con que el criminal permanezca encerrado entre gruesos muros y barrotes de acero.

La existencia de las deficiencias humanas, técnicas y presupuestarias constituye un obstáculo más en la aplicación del tratamiento penitenciario, impidiendo con ello la rehabilitación es decir, no hay selección técnica del personal en todos los niveles, ni especialidades, se carece de una formación académica y en sí adolecemos de una carrera penitenciaria.

En consecuencia, el tratamiento del delincuente apenas si llega a su objetivo en última instancia: la resocialización. En contra de los objetivos de readaptación, se agrava aún más el problema de la delincuencia, al ver al liberado regresar al reclusorio, en la mayoría de los casos, en busca de un techo y abrigo, tal fenómeno dista mucho de probar la excelencia de la prisión, antes bien es demostrativo de su fracaso.

Volver al Índice >> 